\title{
Health beliefs and functional health literacy; Interaction with the pharmaceutical services
}

\author{
Özlem Nazan Erdoğan ${ }^{1, *}$, Ahmet Oğul Araman² \\ 'Department of Pharmacy Management, Faculty of Pharmacy, İstanbul University, 34116, İstanbul, Turkey \\ ${ }^{2}$ Department of Pharmaceutical Technology, Faculty of Pharmacy, İstanbul University, 34116, İstanbul, Turkey
}

Cite this article as: Erdoğan ÖN, Araman AO (2017). Health beliefs and functional health literacy; interaction with the pharmaceutical services. Istanbul J Pharm 47 (2): 68-71.

\begin{abstract}
Pharmacists are supposed to know current issues in social sciences and techniques to understand diseases and illnesses, to empathize with patients and other health professionals, to resolve possible conflicts of interest, to establish an ideal communication, to ensure the rational use of drugs, to reduce the wastage of drugs, and to improve compliance with drug therapy. The purpose of this article was to explain the conceptual framework of the Health Belief Model and Functional Health Literacy, which are recently outstanding topics on healthcare. Further, Pharmacotherapy Literacy is going to be defined as a remarkable subject in the literature. This is a descriptive study illustrating the concepts with the literature.
\end{abstract}

Keywords: Health beliefs, health literacy, pharmacotherapy literacy, public health

\section{INTRODUCTION}

Health Belief Model (HBM) has been developed by Hochbaum, Leventhal, Rosenstock and Kegeles in 1959, the United States of America, in response to the failure of a free or very low-paid Pap smear testing which was early detection of cervical cancer or Tuberculosis screening immunization program as important public health problem (Haefner and Kirscht 1970; Rosenstock 1974). Since then, HBM has been adapted to explain the relationship between beliefs and behavior of individuals about health and illness (Avcl, 2014).

\section{Components of the HBM}

There are six components of the model (Figure 1, Rosenstock et al. 1988; Çenesiz and Atak, 2007).

Perceived sensitivity: the perception of the disease that threaten the health of people; acceptance of the diagnosis, the probability of getting the disease.

Perceived severity: results will occur when the treatment not to be admitted; death, disease, disability, pain include assessment of the possible consequences, such as social losses. If the sensitivity and seriousness are taken together, this is defined as the Perceived threat.

Perceived benefits: due to perform behavior was perceived benefits associated with a reduced risk of developing the disease. People think that preventive health behaviors will give him/her the benefit. This benefit is expected to decrease the risk of developing the disease.

Perceived barriers: barriers to the realization of the proposed believed to difficult behavior or the potential negative aspects of the behavior. People weigh the positive and negative consequences of the behavior. The behavior is performed if perceived 


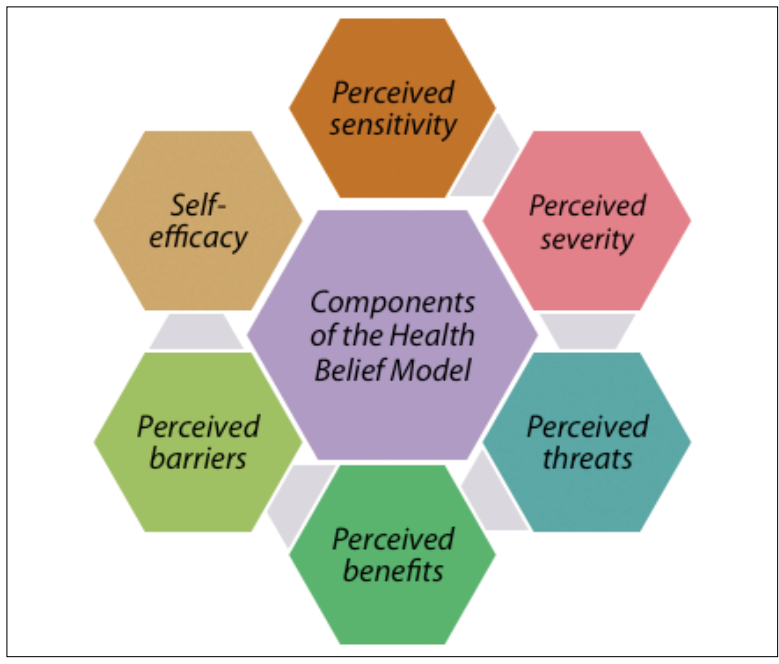

Figure 1. Components of the Health Belief Model (Rosenstock et al. 1988; Cenesiz and Atak, 2007)

susceptibility, severity and benefits reduce the impact of perceived barriers.

In other words, perception of health-related protective factors that prevent or make it difficult to perform a behavior. The most important variables that prevent the realization of protective health behaviors is the difference between the perceived benefits and perceived barriers.

Self- efficacy: one of the components of Albert Bandura's Social Cognitive Theory involves the person's self-belief, determination, self-control related the realization of behavior in order to achieve expected results. This component was added later to the model. Therefore, self-efficacy plays an important role in sustaining the introduction of changes in behavior and attitude.

For a better understanding of well-being, health concept is examined in two dimensions (Figure 2, Birol 2004). When considering the dimensions of health, the issue of health beliefs deserves special attention.

\section{Belief areas that should be primarily discussed (Mat-} thews and Hingson 1977)

\section{A- Beliefs about the disease itself}

This area include the beliefs of the seriousness of the disease and beliefs regarding the possibility of perceptual suffering from those in the future.

\section{Beliefs can be released with some questions;}

1- Why are you worried about high blood pressure?

2- How do you think about your pain now?

3- What do you think about the source of the problem you identify?

4- Do you know one who has cancer like you?

\section{B- Beliefs regarding the benefits}

The model evaluates patient's decision about the acceptance of a treatment plan in terms of cost-benefit analyzes. Many pa-

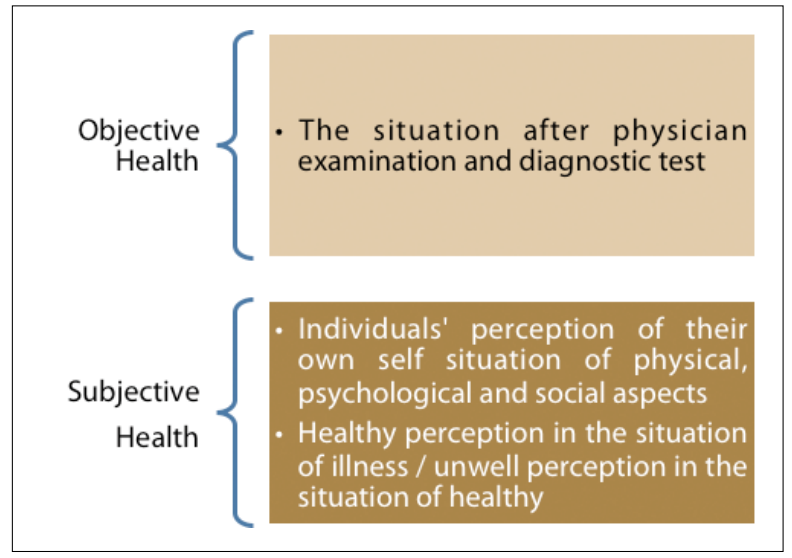

Figure 2. Health dimensions (Birol 2004)

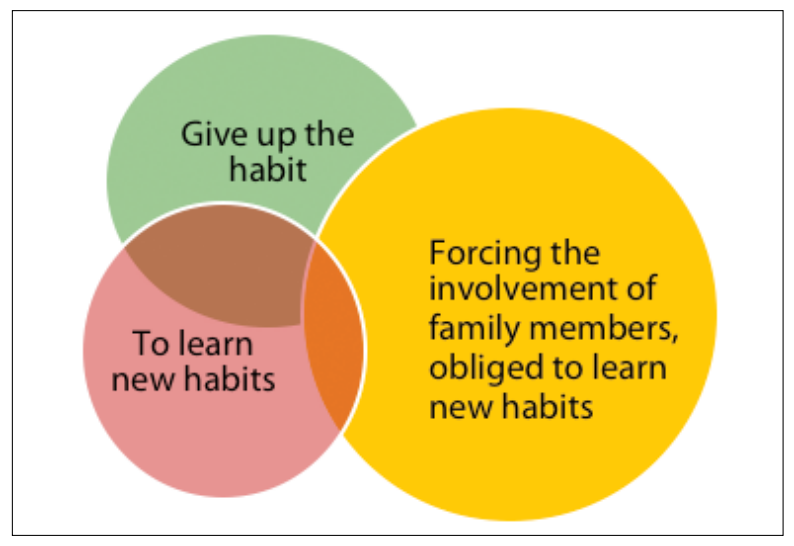

Figure 3. Reflection way of costs

tients who perceive significant cost associated with the treatment plan, are at risk of becoming poorly compatible while rejecting the slightest benefits of treatment. These costs sometimes means different things for the patient in finance (Figure 3).

\section{The questions that would release the beliefs}

1- What are you doing to yourself for your pain?

2- Do you think there might be any problems with these drugs when taken 1 hour before meals?

3- While monthly blood test, is there something bothering you?

4- Have you worried about side effects of this medicine?

\section{The questions that would reveal benefits}

1- Injections, how long do you think it would be dangerous for you?

2- If you forget to take their medication for a night, what do you think would happen?

Knowledge of health beliefs is important in terms of detecting the risk places of poor adherence patients and increasing patient compliance (Figure 4). Beliefs can be changed in important measure by each patient's visit. Health care workers are not the only source of health information for patients. Friends, relatives, magazines, mass communication-media, the diagno- 


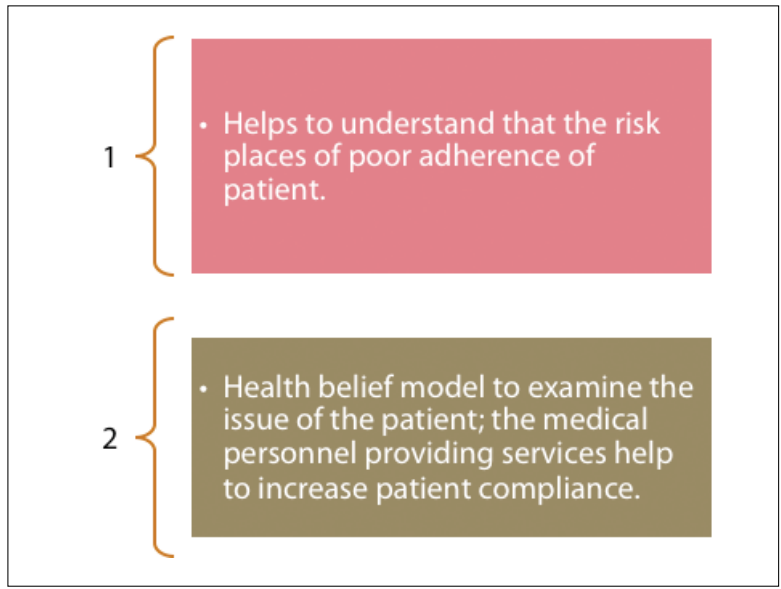

Figure 4. Why is it important to know beliefs? (Manheimer et al. 1973)

sis and treatment of disease may be a source of information in the process. All true or false information provided through these channels will play a role on the patient's compliance.

Health professionals would provide the patient's perspective and try to reveal patient's beliefs as well as to create the impression of patients. Afterwards impressed patients by more attention would respect health professionals with more confidence. These positive sensations could be perceived as a positive move by the patient and cause the patient's health behavior motivation.

Because of the well understood of the relationship between poor literacy skills and health status (Nutbeam 2008); health literacy, functional health literacy, and pharmacotherapy literacy (King et al. 2011) are the critical subjects for pharmaceutical services and pharmacists.

\section{Literacy}

The United Nations Educational, Scientific and Cultural Organization (UNESCO) established the Experimental World Literacy Program in 1966 and characterized literacy as being a fundamental human right. UNESCO defines literacy as "the ability to identify, understand, interpret, create, communicate and compute, using printed and written materials associated with varying contexts. Literacy involves a continuum of learning in enabling individuals to achieve their goals, to develop knowledge and potential, and to participate fully in their community and wider society" (Haefner and Kirscht 1970).

\section{Health Literacy}

Health literacy is an important issue in public health today, especially as patients are taking a greater role in obtaining information about their health (Manganello 2008). It is mentioned that inadequate health literacy is associated with poor health status, less medication adherence, lack of knowledge about disease, worse medical condition and earlier death (Baker et al. 1999; Eyüboğlu and Shultz 2015). Health literacy, according to the American Medical Asssociation (AMA) is that "the constellation of skills involving performing such basic reading and numerical skills as reading medicine bottles and other materials related to health, and comprehending them- which is necessary for functionality in healthcare environments" (AMA 1999).

\section{Functional Health Literacy}

Functional health literacy shows the basic skills of reading and writing about individuals' health. It emphasizes the ability of transfer the individual's health information into their lives (Nutbeam 2008; Aslantekin and Uysal 2014; Sağlık Bakanlığı 2014). "Basic skills in reading, writing and "numeracy" are especially important in the healthcare setting, where patient participation in planning and implementing therapeutic regimens is critical for success" (Parker et al. 1995).

\section{Pharmacothearapy Literacy}

The defenition of Pharmacotherapy Literacy was developed by King et al. because of the complex nature of the pharmacypatient encounter. Pharmacotherapy Literacy is "An individual's ability to abtain, evaluate, calculate, comprehend and properly act upon patient- spesific information concerning pharmacotherapy and pharmaceutical services necessary to make appopriate medication-related decesions, regardless of the mode of content delivery (e.g. written, oral, visual images and symbols"(King et al. 2011).

\section{CONCLUSION}

Today, health care is located in a complex point where advanced technological developments in the health dimension are settled. The role of patients as consumers and individuals are intertwined. Also the individual's functionally health literacy in such a dynamic system is important. Individuals must be strengthened in this dynamic system by developing the level of their health literacy. Therefore, the health beliefs and functional health literacy which are important motivation in improving the health status of the community are critical scientific research topics. According to the scientific literature, health differences levels in community would be reduced by increasing the functional health literacy (Aslantekin and Yumrutaş 2014).

If one was identified as health illiterate, pharmacist would provide an education in terms of drugs. This education includes the use of both education aids and oral counseling methods to achieve the best outcomes of drug therapy (Tcakz et al. 2008). However, when we look at the scientific research conducted on the subject in the European Union between 1991-2005, Turkey ranks $14^{\text {th }}$ with a total of 492 research (Sağlık Bakanlığı 2014). Eventually, first large-scale field research was applied by Sağlık Sen in 2014, Turkey (Sağlık Sen, 2014). According to the summary findings of this study;

- General health literacy index averaged over a 50-point scale was calculated as 30.4. The average index is 33.8 in Europe and the difference is significant. It is pointed out that $64.6 \%$ has insufficient or problematic health literacy. This figure corresponds to an adult population of 35 million. In other words, only $35.4 \%$ of the community has enough or excellent health literacy. This ratio is $52.5 \%$ in the European study.

- $\quad 51.7 \%$ of the population stated that they use drugs without medical advice or prescription. 
- It has been shown that while the age is increasing and education level decreasing, health literacy linearly decreased.

Considering the results of the large scale research applied in Turkey, pharmacist can play a vital role in order to recognize the low health literacy or pharmaceutical literacy (Butler et al. 2013). According to a study focusing on glaucoma control has found that the level of medication adherence has been positively related to health literacy (Muir et al. 2006).

Pharmacists as one of the most accessable providers (Kehoe and Katz 1998) are supposed to be a part of the process of determining health illeterate patient in order to success the aimed results of drug therapy, especially when the half of the population use drugs without medical advice or prescription. Therefore pharmacy education curriculum or courses provided should include critical social subjects mentioned in the article.

\section{REFERENCES}

- $\quad$ AMA (American Medical Association), (1999) Health literacy: Report of the Council on Scientific Affairs, Ad Hoc Committee on Health Literacy for the Council on ScientificAffairs, JAMA 281: 552-557. [CrossRef]

- Aslantekin F, Uysal M (2014) Okuryazarlık ve Sağlık Okuryazarlığı, 19. Eğitim Bilimleri Kongresi http://www.pegem.net/akademi/ kongrebildiri_detay.aspx?id=122975 Accessed 10.11.2014

- Aslantekin F, Yumrutaş M, (2014). Sağlık okuryazarlığı ve ölçümü. TAF PrefMed Bull 13: 327-334. [CrossRef]

- Avcı IA (2014). Meme Kanserinin Erken Tanisi ve Erken Tanıda Sağlık İnanç Modelinin Etkililiği http://www.onkohem.org.tr/ dosyalar/1305477644.pdf Accessed 23.11.2014

- $\quad$ Baker DW, Williams MV, Parker RM, Gazmararian JA, Nurss J (1999). Development of a brief test to measure functional health literacy. Patient Educ Couns 38: 33-42. [CrossRef]

- Birol L (2004). Hemşirelik Süreci: Hemşirelik Bakımında Sistematik Yaklaşım"3. Baskı Etki Matbaacılık, İzmir.

- Butler LM, Devraj R, Santanello C (2013). Design and evaluation of health literacy instructional video for pharmacy students. Innovations in Pharmacy 4: 1-6.
Çenesiz E, Atak N (2007). Türkiye'de Sağlık İnanç Modeli ile Yapılmış Araştırmaların Değerlendirilmesi. Kor Hek 6: 427-434.

- Eyüboğlu E, Schultz PJ (2015). Validation of Turkish health literacy measures. Health Promot Int 31: 355-362. (accessed by https:// www.researchgate.net/publication/270965566_Validation_of_ Turkish_health_literacy_measures 14.09.2017)

- Haefner DP, Kirscht JP (1970). Motivational and behavioral effects of modifying health beliefs. Public Health Rep 85: 478-484. [CrossRef] Kehoe WA, Katz RC (1998). Health behaviors and Pharmacotherapy. Ann Pharmacother 32:1076-1086. [CrossRef]

- $\quad$ King SR, Mccaffrey DJ, Bouldin AS (2011). Health literacy in the pharmacy setting: defining pharmacotherapy literacy. Pharm Pract 9: 213-220. [CrossRef]

- Manganello JA (2008). Health literacy and adolescents: a framework and agenda for future research. Health Edu Res 23: 840-847. [CrossRef]

- Manheimer DI, Davidson ST, Balter MB, Mellinger MD, Cisin IA, Parry HJ (1973). Popular attitudes and beliefs about tranquilizers, Am J Psychiatry 130: 1246-1253. [CrossRef]

- $\quad$ Matthews D, Hingson R (1977). Improving patient compliance. A guide for physicians Med Clin North Am 61: 879-889. [CrossRef]

- Muir KW, Santiago-Turla C, Stinnett SS, Herndon LW, Allingham RR, Challa P, Lee PP (2006). Health literacy and adherence to glaucoma therapy, Am J Ophthalmo/ 142: 223-226. [CrossRef]

- Nutbeam D (2008). The evolving concept of health literacy. Soc Sci Med 67: 2072-2078. [CrossRef]

- Parker RM, Baker DW, Williams MV, Nurss JR (1995). The test of functional health literacy in adults: a new instrument for measuring patients'litearcy skills. J Gen Intern Med 10: 537-541. [CrossRef]

- Rosenstock I (1974). Historical Origins of the Health Belief Model. Health Education Monographs, 2: 328-335. [CrossRef]

- $\quad$ Rosenstock, IM, Strecher VJ, Becker MH (1988). Social Learning Theory and the Health Belief Model. Health Education Quarterly 15:175-183. [CrossRef]

- Sağlık Bakanlığı (2014) http://www.saglik.gov.tr/TR/dosya/172538/h/bfs-soy Accessed 10.11.2014

- S Sağlık Sen (2014) Türkiye sağlık okuryazarlığı araştırması, Sağlık Sen Yayınları, yayın no:25, Ankara.

- Tcakz VL, Metzger A, Pruchnicki MC (2008). Health Literacy in pharmacy. Am J Health-System Pharm 65: 974-981. [CrossRef] 